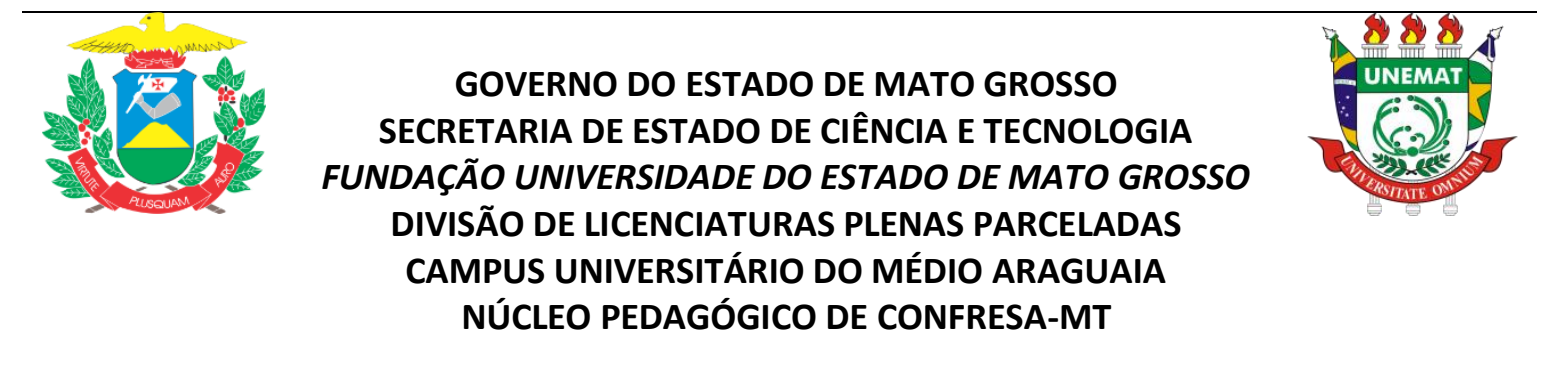

GILSON LOPES DE ALMEIDA

O PROCESSO DE NUCLEAÇÃO DA ESCOLA PAU BRASIL: PERSPECTIVAS DE UMA POLÍTICA PÚBLICA NO MUNICÍPIO DE CONFRESA - MT.

Confresa MT

Janeiro de 2016 


GOVERNO DO ESTADO DE MATO GROSSO
SECRETARIA DE ESTADO DE CIÊNCIA E TECNOLOGIA
FUNDAÇÃO UNIVERSIDADE DO ESTADO DE MATO GROSSO
DIVISÃO DE LICENCIATURAS PLENAS PARCELADAS
CAMPUS UNIVERSITÁRIO DO MÉDIO ARAGUAIA
NÚCLEO PEDAGÓGICO DE CONFRESA-MT

GILSON LOPES DE ALMEIDA

\section{O PROCESSO DE NUCLEAÇÃO DA ESCOLA PAU BRASIL: PERSPECTIVAS DE UMA POLÍTICA PÚBLICA NO MUNICÍPIO DE CONFRESA - MT.}

Trabalho apresentado como requisito parcial para obtenção de aprovação no Curso de Licenciatura Plena e Bacharelado em Ciências Sociais da Universidade do Estado de Mato Grosso.

BANCA EXAMINADORA

Prof.

Prof.

Confresa, 2016. 
Siglas e abreviações

Tabelas

Mapas

Gráficos 
Agradecimentos

Em primeiro lugar agradeço ao soberano senhor meu Deus que quando estive fraco ele me deu força, quando estive cansado ele me fortaleceu, aos momentos que orei e pedi sabedoria fui atendido, nunca fui não sou e nem serei nada sem o consentimento do todo poderoso em quem creio e confio plenamente. Estendo os agradecimentos a UNEMAT - Universidade do Estado de Mato Grosso e todo corpo docente da instituição em especifico meu orientador Edyvamilton, Direção $e$ Coordenação na pessoa do Tonico e Maria do Rosário que fizeram tudo que estavam em seu alcance para essa vitória que ora recebemos. Também, meus agradecimentos em especial a minha esposa e companheira Domingas Lódia dos Santos Almeida, meus filhos Diogo Vinicius dos Santos Almeida e Jessica dos Santos Almeida pelo apoio familiar quando deles precisei.

Ao final, agradeço a todos meus colegas de curso, que juntamente comigo buscou fortes interesses no agregar valores e conhecimentos doravante ao curso. 


\section{Sumário}

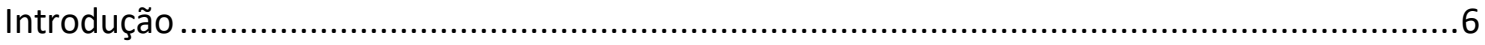

Cap. 1 Gestão Pública em Educação: desafios contemporâneos .............................................8

1.1 - A LDB e a Escola do campo: gestão e desafios ........................................................

1.2 - Diálogos como os pensadores: a educação do campo e sua relevância social...............11

Cap. 2 Da teoria à prática da prática à teoria: A escola do campo Pau-Brasil em construção....11

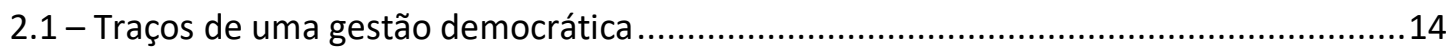

Cap 3 Uma cidade, uma comunidade e uma Escola nucleada: desafios de gestão.....................16

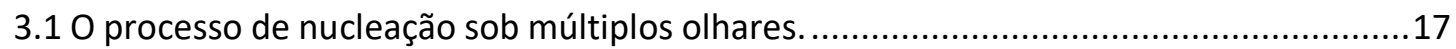

3.2 - Mapas organizacionais: as escolas sob a jurisdição da nucleação ................................18

3.2.1 - Escola Municipal Novo Horizonte ...................................................................19

3.2.2 - Escola Municipal Novo Horizonte (extensão) ........................................................21

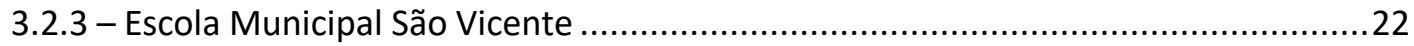

3.3 - Revelando a Nucleação: comparando casos .............................................................23

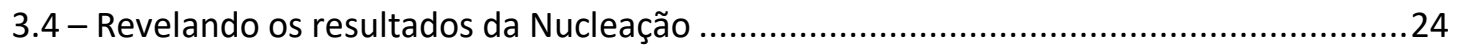

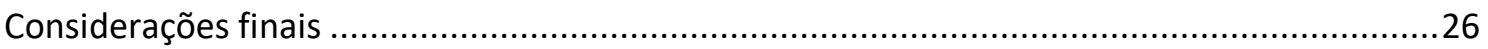

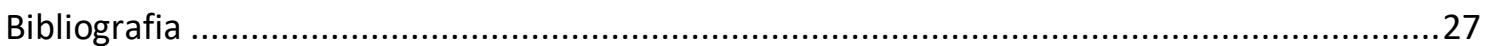

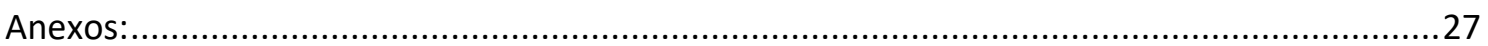




\section{Introdução}

A educação do campo no Brasil é fruto de lutas dos trabalhadores do campo organizados por meio de movimentos e reivindicações para que igualmente aos filhos das famílias urbanas, estes pudessem ter acesso à escola e a educação formal. Pois, enquanto trabalhadores e trabalhadoras rurais pudessem não só ter acesso à alfabetização, mas sim, pudessem reconhecer suas causas enquanto camponeses as garantias do Estado na construção de politicas públicas transformar suas realidades sócias históricas.

Como instrumento peculiar das primeiras conquistas pode ser destacado o PRONERA (Programa Nacional de Educação na Reforma Agraria), a partir do qual, se deu a criação das escolas do campo e no campo para atender especificamente a comunidade da região que ali moram dentro de um Assentamento. Assim não haveria a necessidade de terem que sair do campo para estudar nas escolas urbanas, uma vez que a permanência deles junto às famílias possibilitaria aumento na produção, engajados nas atividades produtivas da família.

Esse trabalho acadêmico tem por objetivo conhecer os impactos em relação ao processo da nucleação da escola Municipal Rural Pau Brasil na organização e oferta dos serviços pela escola municipal Pau Brasil elaborando uma análise acerca das políticas públicas para a educação implantada pela secretaria municipal de educação de Confresa / MT, considerando o contexto específico em que insere o processo de nucleação. Resgatar a história do assentamento do P.A. São Vicente, estabelecendo ligações históricas e culturais arraigadas dentro ao comércio madeireiro e sua economia; entrevista; mapas e outros materiais informativos procurando evidenciar como aconteceu o processo e seu desenvolvimento e qual impacto causado pelo processo de nucleação às famílias (pais e alunos) da escola municipal Pau Brasil?

Conhecendo a complexidade sócia econômica e diversidade cultural das pessoas que vivem no campo, consideramos essenciais para a compreensão do significado da escola enquanto política pública educacional: Como foi concebido o processo de nucleação, quem foram seus idealizadores e quais as razões de sua criação? Como foi implantado? Como os professores e os pais veem esse processo? Quais os aspectos positivos e negativos da nucleação? É possível afirmar que a nucleação acabou contribuindo para a evasão dos alunos? O que mudou na prática pedagógica dos professores após nucleação? 
Entendemos que, ao responder a problemática que norteou a pesquisa possibilitou traçar o percurso bem como revelar aspectos importantes para $o$ fortalecimento da educação no município de Confresa por meio de ações afirmativa enquanto política pública educacional.

Este trabalho monográfico está estruturado em introdução e três capítulos. Na introdução revelamos o objeto e a relevância da pesquisa, a problemática, hipóteses e possíveis resultados. No primeiro capitulo intitulada Gestão Pública em Educação: desafios contemporâneos procuraram apresentar mediante a legislação, como é entendido o processo de gestão pública em educação. No capítulo II que tem por título Da teoria à prática da prática à teoria: A escola do campo Pau Brasil em construção apresentou a Escola Pau Brasil e seu contorno sócio cultural e organizacional. No terceiro capítulo Uma cidade, uma comunidade e uma Escola nucleada: desafio de gestão apresentou o contorno do processo de nucleação bem como os aspectos de sua implantação sob os olhares dos protagonistas. Por fim apresentamos as conclusões obtidas a partir da pesquisa abrindo horizontes para novos olhares sobre o tema. 


\section{Cap. 1 Gestão Pública em Educação: desafios contemporâneos}

É interessante fazer uma analise inicial antes de relatar as condições contemporâneas e depois dar continuidade ao processo educacional em especial do campo, porque hoje seria bem mais fácil entender os agravantes que existente na educação. Ao longo da história, houve conquistas, derrotas, tanto nas questões politicas, estruturais, pedagógicas, curriculares, saíram de uma educação tradicional, severa, antiquada e ultrapassada para uma educação moderna, visionaria e cheia de oportunidades. Diante das politica públicas, acertaram nas nucleações, melhores condições estruturais e profissionais, com formação da maioria dos professores e a organização do transporte escolar com a parceria do governo do Estado e FNDE. Conquistas foram advindas e bem vindas. O processo educacional deu-se inicio com os gestores anteriores que alavancaram um projeto audacioso e inovador com a criação de núcleos escolares que hoje podemos afirmar categoricamente, que deu certo e funcionou com muita luta e perseverança dos envolvidos no contexto educacional escolar. Por outro lado, nota-se que na cidade as salas de aula encontram-se superlotadas e em algumas delas tendo que criar um horário chamado de intermediário para suprir as necessidades das demandas. Tem que avançar ainda mais, repensar o piso nacional, o plano de cargo e salários, conceder as licenças por direito, fazer as elevações necessárias e legais.

\section{1 - A LDB e a Escola do campo: gestão e desafios}

A LDB (Lei de diretrizes e Bases da Educação Nacional) n ${ }^{\circ} 9.393$ de 20 de dezembro de 1996, em seu bojo prisma de forma estrutural definindo orientações e regras em seus artigos e afins de gestão pública em educação da melhor maneira organizacional quanto ao funcionamento do ensino quanto aos aspectos políticos, administrativos, financeiros, tecnológicos, culturais, artísticos e pedagógicos, com a finalidade de dar transparência às suas ações e atos e possibilitar à comunidade escolar e local a aquisição de conhecimentos, saberes, ideias e sonhos num processo de aprender, inventar, criar, dialogar, construir, transformar e ensinar. Norteia princípios da igualdade, liberdade, pluralismo, respeito, coexistência, gratuidade e valorização. 
Determina competências municipais, estaduais e federais no tocante as responsabilidades e deveres de cada um, tanto pública e privada, delimitando as modalidades das etapas da educação em todos os níveis. Em especial, cito um artigo e seus incisos em referencia a escola do campo.

“Art. 28 - Na oferta de educação básica para a população rural, os sistemas de ensino promoverão as adaptações necessárias à sua adequação às peculiaridades da vida rural e de cada região, especialmente: I - conteúdos curriculares e metodologias apropriadas às reais necessidades e interesses dos alunos da zona rural; II - organização escolar própria, incluindo adequação do calendário escolar às fases do ciclo agrícola e às condições climáticas; III - adequação à natureza do trabalho na zona rural. Parágrafo único. O fechamento de escolas do campo, indígenas e quilombolas será precedido de manifestação do órgão normativo do respectivo sistema de ensino, que considerará a justificativa apresentada pela Secretaria de Educação, a análise do diagnóstico do impacto da ação e a manifestação da comunidade escolar."

As dificuldades encontradas pelos professores e alunos estando no campo estão relacionadas em diversas modalidades elencadas pela comunidade escolar que interfere diretamente no processo educacional. A infraestrutura inadequada, a partir das salas sem ventilação, cercada por tábuas, tornando-as quentes e insuportáveis de aguentar. Faltam meios de comunicação para pesquisar bem como uma internet para professores e alunos. Outras dificuldades estão relacionadas por falta de equipamentos para produção de aulas diferenciadas, como um retroprojetor de imagens, computadores, e até um aparelho de DVD e televisão. Ainda, no contexto sobre aprendizado os alunos deixam de aprender quando professor dando aula fora da sua formação especifica, não produz efeito adequado ou necessário. Ainda faltam materiais pedagógicos para as oficinas, para educação física, às vezes falta até mesmo de merenda escolar. Não bastassem para completar as dificuldades, as escolas do campo que mais utilizam o transporte escolar também esta sendo afetado que quebra frequentemente ficando dias e dias e os alunos sem vir para escola. 
Definir escola do campo não por estar no campo, mas pelas práticas que fazem no campo, das necessidades em adequar a pedagogia na forma mais simples de se fazer acontecer. Nesse fazer acontecer incluímos a construção dos projetos políticopedagógicos das escolas do campo em que nesta perspectiva, possibilidades de múltiplas aprendizagens, pois permite diálogo entre os saberes diversos e as ciências. A Escola do Campo assim entendida e construída, não se restringe apenas em um espaço físico, onde se teoriza, mas torna-se um centro dinâmico, de irradiação, de reflexão e de práxis, ações que contribuem para a ressignificação de valores, de identidade e de pertencimento. Processos que fortalecem o entendimento do processo inconcluso pelo qual veicula o ser humano no mundo, contribuindo para a construção efetiva do que é ser humano em uma sociedade mecanizada.

Numa breve retomada ao ponto de partida, podemos citar uma grande conquista dos movimentos sociais, pela criação do Estatuto da Terra, com disposições pela Reforma Agrária e Desenvolvimento Rural. Para tanto, o processo educacional é criado a Reforma Universitária em 1968 e depois as Escolas Família Agrícolas de Ensino Médio. Nos anos 80 a CUT (Central Única dos trabalhadores) e MST (Movimento dos Sem Terras) travou lutas com movimentos expressivos reivindicando a Reforma Agraria e Educação do Campo. A primeira conquista aconteceu com a inclusão da Educação Básica do Campo na LDB 9394/96 tratado no artigo 28 que diz o seguinte: ' $\mathrm{Na}$ oferta de educação básica para a população rural, os sistemas de ensino promoverão as adaptações necessárias à sua adequação às peculiaridades da vida rural e de cada região, especialmente: I - conteúdos curriculares e metodologias apropriadas às reais necessidades e interesses dos alunos da zona rural; II - organização escolar própria, incluindo adequação do calendário escolar às fases do ciclo agrícola e as condições climáticas; III - adequação à natureza do trabalho na zona rural”.

A Educação do Campo no Estado de Mato Grosso - um processo em construção, pautadas em quatro temáticas pedagógicas a seguir: A Construção da Cidadania, Terra e Trabalho, Os Povos do Campo: identidades, lutas e organizações e Sociedades Sustentáveis.

METODOLOGIAS DAS ESCOLAS DO CAMPO - Elas devem ser voltadas para o campo, inovadoras, criativas e contextualizadas para dar suporte pedagógico a 
essa demanda educativa diferenciada. Portanto, pretende-se enfatizar que todos os pensadores, acadêmicos, formuladores, pesquisadores, educadores, governantes, movimentos sociais e educandos são os sujeitos desse processo. Todos participam da formulação de uma Política de Educação do Campo, junto com outros que acreditam na ousadia e na superação de modelos hegemônicos.

A Pedagogia da alternância, Complexo Temático, Pedagogia de Projetos, Tema Gerador e Pesquisação são iniciativas metodológicas que as escolas possam assumir em seu trabalho pedagógico usando com coerência com a vinculação, articulação interativa com a vida e a realidade dos povos dos campos, suas lutas e experiências, seus saberes e suas organizações e seus movimentos e limites e suas potencialidades. Compromisso de realizar o processo ensino-aprendizagem respeitando, valorizando e incorporando saberes, experiências e conhecimentos dos povos do campo. Articulação e promoção dos diversos espaços e tempos pedagógicos e o compromisso com a transformação do campo, a partir dos projetos emancipatórios dos povos do campo.

\section{2 - Diálogos como os pensadores: a educação do campo e sua relevância social.}

Segundo Caldart (2000), a proposta pedagógica do MST está vinculada a princípios organizativos que fundamentam a existência do próprio Movimento. A autora afirma que a um projeto de sociedade está vinculado um projeto de ser humano ou, no dizer de Paulo Freire, de humanização. Este ser humano, por sua vez, se constrói na atuação coletiva do Movimento, através da intencionalidade pedagógica de cada momento que se vive no MST. As pedagogias que foram assumidas nasceram da luta cotidiana do Movimento e, segundo a mesma autora, são elas: pedagogia da luta social, pedagogia da organização coletiva, pedagogia da terra, pedagogia da cultura e pedagogia da história.

Para Caldart, a educação do campo tem urgência e parafraseia o seguinte pensamento: "nosso tempo é de urgências. Urge o tempo da luta de todos pela dignidade roubada de cada um de nós. Mas a sabedoria camponesa nos ensina que esta luta urgente é uma luta 
de resistência e persistência. É preciso trabalhar agora pensando já na próxima safra, preservando com cuidado as sementes e prestando atenção no tempo certo de seu plantio." nestes textos trabalham com formação e particularmente com formação de educadores. Porque acreditam que esta sementeira vai "garantir a próxima planta".

Segundo Caldart, a Educação do Campo se constitui a partir de uma contradição "que é a própria contradição de classe no campo. Pois existe uma incompatibilidade de origem entre a agricultura capitalista e a Educação no e do Campo, exatamente porque a primeira sobrevive da exclusão e da morte dos camponeses, que são sujeitos principais da Educação do Campo" (2004, p.19). A agricultura capitalista destrói a diversidade existente na natureza dos camponeses, dos quilombolas e dos povos indígenas; enquanto que a Educação do Campo é a luta dos camponeses contra o modelo de agricultura do agronegócio, que gera exploração, submissão e aumento da pobreza no campo. Esse modelo de produção agrária, que traz o empobrecimento para o campo e, consequentemente, para os trabalhadores rurais, está enraizado na estrutura agrária, na concentração de terra pela oligarquia brasileira, desde a colonização.

O desafio está na consolidação da proposta, dos conteúdos, do método de ensino e da efetivação do projeto político pedagógico que é a coluna dorsal da escola e da organização do trabalho pedagógico, e que depende de um conjunto de ideias e muito esforço coletivo e individual dos envolvidos e comprometido com a Educação do Campo que emerge da luta social para contrapor a educação fragmentada do sistema vigente (Andrade, 2006. p. 25.).

Para reafirmar a esse tipo de sociedade e de escola é que os movimentos sociais do campo, desde a primeira Conferência Nacional por uma Educação Básica do Campo, buscam garantir que os Projetos Políticos Pedagógicos das escolas do campo estejam vinculados ao desenvolvimento da comunidade e seja dada a garantia da participação amplamente discutida pelos sujeitos e pensar como os projetos governamentais se expressam como políticas públicas, tratando de Projeto Político Pedagógico (PPP) como política pública para a educação do campo brasileira. De modo geral, a constituição do PPP tem sido uma política de governo e não uma política pública, o que impede, muitas vezes, a sua continuidade. 
A Educação do Campo dialoga com a pedagogia crítica da educação, ou seja, dialoga com a pedagogia progressista, que busca a formação do ser humano e a igualdade social. Essa corrente pedagógica muito contribui para o avanço da dimensão do trabalho, da cultura e do direito, além da autonomia e da auto-organização dos sujeitos envolvidos no processo educativo. Como podemos perceber, a educação do campo dialoga com a fonte da Pedagogia do Oprimido (Freire, 1987) que se fundamenta na matriz pedagógica da cultura, do trabalho, da conscientização.

\section{Cap. 2 Da teoria à prática da prática à teoria: A escola do campo Pau-Brasil em construção}

A Escola Rural Municipal Pau Brasil foi criada pelo Decreto número 093/1996, possui autorização regulamentada pela Resolução 098/99 - CEE/MT (Conselho Estadual de Educação do Estado de Mato Grosso) está localizada às margens da MT 430, km 63, no Projeto de Assentamento São Vicente, no Distrito da Vila Esperança, na zona rural, com CEP 78652-000 neste município de Confresa, Estado de Mato Grosso. Essa escola atende atualmente em seus níveis e modalidade de ensino a clientela da préescola, ensino fundamental primeiro e segundo seguimento que funciona no período intermediário em regime externato, atendendo aproximadamente 155 (cento e cinquenta e cinco) alunos, sob a Direção do Senhor Domingos Matos na gestão do Prefeito Gaspar Domingos Lazzari e dirigente municipal de educação a senhora professora Agenora Morais Miranda.

A escola tem um quadro de profissionais que estão a sua disposição e ajudam na manutenção e desenvolvimento das atividades, de acordo com a tabela a seguir.

\section{Tabela I - Demonstrativo da quantidade de funcionários da escola}

\begin{tabular}{|l|l|l|l|}
\hline \multicolumn{2}{|c}{ NOME } & HABILITAÇÃO & SITUAÇÃO \\
\hline $\mathbf{1}$ & Eva Cristina Ferreira da Silva & Licenciatura em Pedagogia & Efetiva \\
\hline $\mathbf{3}$ & Gilson Lopes de Almeida & Profissionalizante /Magistério & Efetivo \\
\hline $\mathbf{4}$ & Mirian Aguiar da Silva & Profissionalizante/Magistério & Efetiva \\
\hline $\mathbf{5}$ & Divina Diniz Fernandes & Licenciatura em letras & Efetiva \\
\hline $\mathbf{6}$ & Suênia Arruda Silva & Licenciatura em pedagogia & Efetiva \\
\hline $\mathbf{7}$ & Cheila pereira Toledo & Técnica em infraestrutura & Efetiva \\
\hline $\mathbf{8}$ & Manoel & Técnico em infraestrutura & Efetivo \\
\hline $\mathbf{9}$ & Poliana Candido Caetano & Ensino Médio & Interina \\
\hline
\end{tabular}




\begin{tabular}{|l|l|l|l|}
\hline $\mathbf{1 0}$ & Sandra Martins & Ensino Médio & Interina \\
\hline $\mathbf{1 1}$ & Luregina carvalho & Ensino Médio & Interina \\
\hline $\mathbf{1 2}$ & Teobaldo Tavares & Ensino fundamental incompleto & Interino \\
\hline
\end{tabular}

Fonte: PPP- Projeto Político Pedagógico-2013.

Ao observar o quadro acima podemos observar que a escola possui dozes funcionários, sendo sete efetivos e cinco interinos, os professores são cinco efetivos e dois interinos e o apoio são cinco: dois guardas, um efetivo e um interino, dois apoio na limpeza, um efetivo e um interino e uma na merenda que é efetiva.

A escola atende 155 alunos da educação infantil ao nono ano do Ensino Fundamental de nove anos, onde 60 são transportados, possui seis linhas de transporte cinco é utilizado o ônibus da prefeitura onde os motoristas são pagos por hora de trabalho pela prefeitura e uma o carro é alugado e roda por quilômetros, ou seja, a prefeitura paga por quilometro rodado. Desde 2010 a escola recebeu autonomia da SMEELC (secretaria municipal de educação esporte lazer e cultura) de Confresa para construir seu PPP (projeto político pedagógico) onde o mesmo consta todas as informações da escola desde sua missão até o quadro de funcionários e foi construído por todo corpo escolar (pais, alunos, professores e CDCE) com ajuda da secretaria de educação.

Percebe se ao ler o PPP da escola precisa se adequar, pois ainda precisa de muitas mudanças para respeitar o modo de vida do campo, começando pela adaptação do calendário escolar, o horário das aulas e capacitação para os professores para entender como se deve proceder em uma escola do e no campo.

\section{1 - Traços de uma gestão democrática}

Diante dos processos atribuídos ao aparato de políticas públicas nas escolas do campo, a criação dos Conselhos Escolares foi primordial pela sustentabilidade da gestão, viabilizando e interagindo parceria no processo pedagógico, conduzindo mediação com atores escolares (pais de alunos e escola), gerindo recursos para suprir as demandas da comunidade escolar que possa fluir rendimentos na educação dos alunos, mediante planos de aplicação dos recursos oriundos do MEC e Prefeitura, aprovados pelos conselheiros representantes de pais, alunos e funcionários pautados pela gestão democrática em sua totalidade organizacional. 
O conselho deliberativo da escola foi criado no ano de 2005 onde a primeira gestão foi formada:

\section{Tabela II- Dos primeiros conselheiros da escola}

\begin{tabular}{ll}
\hline Conselheiros & Funções \\
\hline Gilson Lopes de Almeida & Presidente \\
\hline Lódia Santos Almeida & Conselheiro \\
\hline Suênia arruda silva & Secretaria \\
\hline Sebastiana de Souza & Conselheira \\
\hline Celita Nunes Cardoso & Conselheira \\
\hline Matilde Muniz da silva & Conselheira \\
\hline Rosimar Márcia da silva & Conselheira \\
\hline
\end{tabular}

Fonte: PPP- Projeto Político Pedagógico-2013.

Conforme a tabela acima o primeiro conselho foi constituído pelas seguintes pessoas Presidente Gilson Lopes de Almeida, secretaria Suênia Arruda Silva e as conselheiras Domingas Lódia Santos Almeida, Sebastiana de Souza, Celita Nunes Cardoso, Matilde Muniz da silva, Rosimar Márcia da Silva, Edinaira Alves Dutra. Esse conselho já passou várias gestões onde cada uma fica no mandato por dois anos assim como diz a ata de criação.

A escola possui diretor e coordenador mais os dois são indicados pela secretaria de educação e o diretor é o mesmo para todas as escolas do campo e ele mora na sede do município chegando a ficar até 20 dias sem ir à unidade escolar e o coordenador tendo que desempenhar as duas funções e com certeza nenhuma das duas saem com perfeição.

A escola adotou o ensino fundamental de nove anos e atende os alunos de $1^{\circ}$ ao $9^{\circ}$ e a educação infantil de 4 e 5 anos. Devido à pequena quantidade de alunos na sala a partir de 2013 as salas tem sido multisseriadas, ou seja, junta as salas com outra para que forme turmas maior sendo assim o professor terá que trabalhar com dois anos numa sala só, como exemplo $1^{\circ}$ e $2^{\circ}, 3^{\circ}$ e $4^{\circ}$. 


\section{Cap. 3 Uma cidade, uma comunidade e uma Escola nucleada: desafios de gestão.}

Confresa esta localizada no extremo norte mato-grossense, considerada o município mais populoso da microrregião do norte Araguaia com uma população de aproximadamente 35.000 mil habitantes, o mesmo esta separado da capital, Cuiabá com uma distancia de $1.180 \mathrm{~km}$. Em Confresa há grande concentração de assentamentos rurais, prevalecendo assim, a agricultura familiar, com o elevado contingente de pessoas que migraram para o campo na década de 1990 atraído pelo sonho de conquistar a terra própria e o plantio de bananas, ocorre a necessidade de criar escolas (POLITICAS PUBLICA) para atender as demandas dos filhos de agricultores familiares que ali chegavam, visando fortalecer o interesse dos mesmos em ficarem nas propriedades, no entanto esse procedimento ocorreu de forma desordenada, uma vez que se criava uma escola e a partir desta extraiam varias extensões, buscando assim, a priorização dos alunos para que estudassem o mais próximo possível de suas casas, porem com tantas unidades torna-se "excessivo" os gastos com a educação no município.

Neste sentido surge a necessidade de se pensar meios para a contenção desses gastos (POLITICAS PUBLICAS), e foi pensando nessa problemática e na qualidade da educação que segundo os gestores da época, criaram políticas para a nucleação dessas escolas situadas em diversos assentamentos no município de Confresa. A nucleação das escolas do campo no município de Confresa MT aconteceu de forma "acelerada", deixando muitas pessoas confusas, sem entender bem o ocorrido, em "colocação" a essa falta de entendimento buscamos compreender e escrever esse processo histórico a fim de possibilitar uma maior compreensão, assinalando os pontos positivos bem como os negativos em relação a nucleação das escolas do campo no município de Confresa MT.

Nessa circunstância havia também inúmeras escolas distribuídas pelos assentamentos rurais com o objetivo de atender os anseios da população ali existente, e nessa perspectiva começam a criarem-se escolinhas por toda parte dentro do município, chegando a concretizar o registro de 83 até o ano de 1997. 
Ao analisarmos as tabelas mais a frente exposta neste texto, poderemos observar que o processo histórico educacional em Confresa-MT, ao longo de 20 anos foi marcado por lutas e conquistas e hoje podemos dizer que ainda não temos uma educação de qualidade nas escolas do campo.

\subsection{0 processo de nucleação sob múltiplos olhares.}

Especificamente na referida escola aconteceu conforme as seguintes necessidades: criam-se varias escolas próximas umas das outras, sendo elas na maioria localizada na área rural denominada "Escola do Campo" e algumas delas de com cobertura de palha, cercada de pau ou tabuas. Com o elevado contingente de pessoas que migraram para o campo nos anos 90, ocorre a necessidade de criar escolas para atender as demandas dos filhos de camponeses que ali chegavam visando fortalecer o interesse dos mesmos em ficarem nas propriedades, no entanto esse procedimento ocorreu de forma desordenada, uma vez que se criava uma escola e a partir desta extraíam varias extensões buscando assim a priorização dos alunos para que estudassem o mais próximo possível de suas casas, porem com tantas unidades torna-se excessivo o gasto com a educação no município, nesse sentido surge a necessidade de se pensar meios para a contenção desses gastos, e foi pensando nessa problemática e na qualidade da educação que segundo os gestores, criaram políticas para a nucleação dessas escolas situadas por todas as partes, nos quatro cantos do município.

O processo de nucleação dessa escola do município de Confresa MT aconteceu de forma acelerada, deixando muitas pessoas confusas, sem entender bem o ocorrido, em colocação a essa falta de entendimento buscamos compreender e escrever esse processo histórico a fim de levar as pessoas a essa compreensão, assinalando os pontos positivos bem como os negativos. 


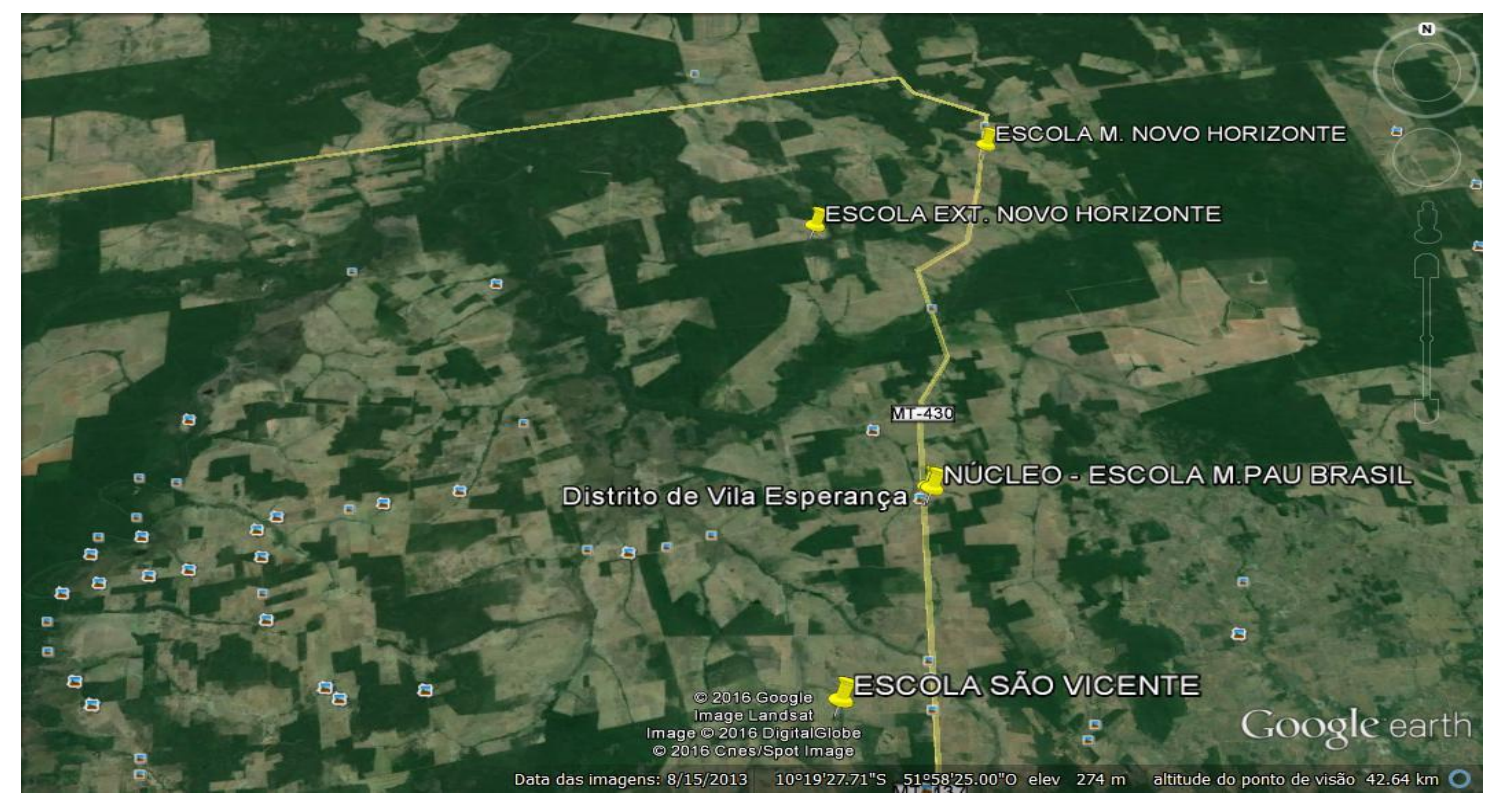

\section{2 - Mapas organizacionais: as escolas sob a jurisdição da nucleação}

O município de Confresa possui 14 Projetos de Assentamentos sendo eles: P.A Fartura; Jacaré Valente, São Vicente; Confresa Roncador; Independente I; Independente II; Piracicaba; Xavante; Porto Esperança; Santo Antônio do Fontoura I, Santo Antônio do Fontoura II; Santo Antônio do Fontoura III; Bridão Brasileiro e Canta Galo e a Gleba porta da Amazônia, conforme dados da SMA- Secretaria Municipal de Agricultura de Confresa- MT em 2013.

Consiste que a economia que predomina é a demanda da agricultura familiar, "com o elevado contingente de pessoas que migraram para o campo na década de 1990, as quais foram atraídas pelo sonho de conquistar a terra própria e o plantio de bananas". Diante do contexto pesquisado e exposto sobre a referida nucleação da Escola Municipal Pau Brasil que esta situada dentro do Projeto de Assentamento São Vicente, composto por 368 lotes que variam de 50 a 100 hectares, seus parceleiros são criadores de gado de leite e corte ainda nas condições arcaicas sem técnicas necessárias da agropecuária, extração e venda de madeiras para as serrarias existentes na Agrovila Três Flechas. Em condições diferentes estão próximos do Assentamento São Vicente as Glebas Três Flechas, Naves e Novo Horizonte (terras ocupadas por terceiros) também criadores de gado de leite e corte. Outra escola nucleada foi a Escola Municipal Jacaré Valente, dentro do Projeto de Assentamento Jacaré Valente I,II e III e Projeto de 
Assentamento Confresa Roncador, com a mesma economia, (gado corte e leite ). Outra Escola Novo Planalto, dentro do Projeto de Assentamento Fartura, mantendo a mesma economia da criação de gado (leite e corte). Outra Escola Santo Antônio, dentro do Projeto de Assentamento Santo Antônio I, II, e III com economia da criação de gado (leite e corte). Escola Estadual Sol Nascente, dentro do Projeto de assentamento Lumiar, Com economia criação de gado. Escola Municipal Vida Esperança, Projeto de $\underline{\text { Assentamento Palmeiras, setor Palmeiras. Escola municipal Bridão, dentro do Projeto }}$ de Assentamento Bridão Brasileira, também com a mesma economia dos demais. Portanto, ao realizar a reforma agraria e implantar os benefícios, os projetos implantados nos assentamentos na maioria foram pela criação de gado. Independente I e II. Essa é a realidade dos assentamentos, que foi primeira mente criação de gado de corte, e por ultimo nos três anos começaram a criar gado leiteiro para ordenha e renda.

\subsection{1 - Escola Municipal Novo Horizonte}

A Escola Municipal Novo Horizonte era localizada a vinte quilômetros da escola Pau Brasil, dentro de uma comunidade denominada "Gleba Novo Horizonte" onde as terras foram griladas por posseiros e nelas aglomerou-se aproximadamente 25 (vinte e cinco) famílias, porém, depois de alguns anos surgiu documentação das terras e consequentemente um dono. Essas famílias viviam da agricultura familiar e criação de gado de corte, de suínos e aves. Nessa escola havia cinco professores com formação de ensino médio, e salas multisseriadas com alunos da primeira $1^{\mathrm{a}}$ a $2^{\mathrm{a}}$ série $3^{\mathrm{a}}$ a $4^{\mathrm{a}}$ série com quinze alunos em cada turma e outra turma da $5^{\mathrm{a}}$ a $8^{\mathrm{a}}$ série com 18 a 20 alunos. As salas de aulas dessa referida escola, duas eram de tábuas e uma de materiais de construção. Não havia transporte escolar e nem banheiros nos primeiros anos, somente depois que construíram "privadas". A merenda era composta de bolacha e suco sendo o cardápio todos os dias da semana.

Para melhores esclarecimentos colhi o depoimento da professora Eva Cristina Ferreira da Silva com o seguinte relato: "A mudança das escolas rurais no município de Confresa iniciou-se em 2005 e se tornou real no ano de 2006, onde as escolas da região Novo Horizonte foram nucleadas na Agrovila Três Flechas P.A. São Vicente, Escola Municipal Pau Brasil. Até então havia várias pequenas escolas em situações bem 
precárias nas localidades. Passo aqui relatar um pouco da experiência que vivi na Escola Municipal Novo Horizonte - Gleba Novo Horizonte MT- 430 no ano de 2005, quando se iniciava a discussão no município. Destaco ainda que vivi 7 anos de experiência em outras escolas menores e com muito menor estrutura que a escola citada. As construções eram bem precárias, na Vila Novo Horizonte havia uma única sala construída de alvenaria, mas como tínhamos naquela naquele ano 3(três) turmas, uma se abrigava nessa sala e as outras duas ficavam em uma sala bem precária, era construída de madeira e telhas "eternit" porém estava muito danificadas, quase caindo sobre os alunos, após uns 3(três) meses que estava trabalhando na escola ao chegar um dia pela manha deparei com esta sala completamente destruída pelos alunos que acreditavam que não podiam mais se arriscarem utilizando um espaço tão precário e com riscos de desabar a qualquer momento. Logo em parceria com prefeitura e comunidade construiuse uma nova escola também de madeira, com telhas "eternit" e piso "queimado", duas salas ampla que foi suficiente para atender as turmas naquele momento. Os banheiros eram "privadas" em algumas escolas, em outras os alunos precisavam ir ao mato mesmo. Não haviam nas escolas das localidades cantinas para o preparo da merenda escolar nem cozinheira, geralmente o professor preparava o lanche em casa e levava nas marmitas e depois levava a louça para lavar em casa e na maioria das vezes morava distante da escola, como era meu caso $(7 \mathrm{~km})$ e a locomoção era com uso de bicicleta. $\mathrm{Na}$ maioria das vezes a merenda era suco e bolacha por ser mais fácil de preparar e servir com a situação que tínhamos. Algumas crianças moravam distante da escola até 10(dez) km e não havia ainda na região o transporte escolar, então eles iam de bicicleta os que possuíam, a cavalo e mesmo de pé era muito sofrido. Muito poucos professores eram formados. Eu participei do Proformação em 1999/2000 e formei em magistério, mas poucos professores na região tinham formação.

A princípio a comunidade lutou muito contra a nucleação, não queriam que seus filhos fossem levados para outra localidade, tiveram muita resistência porem no inicio de 2006 os alunos foram levados para Escola Municipal Pau Brasil - Três Flechas. Inicialmente a situação não era boa também pois as estradas não eram boas, a estrutura física da escola também não, pois, para receber todos esses alunos as salas de alvenaria não eram suficientes (4) e então foi construído um barracão utilizando os próprios materiais das escolinhas e dividido em umas 5 (cinco) salas para conseguir atender a todos os alunos. Permanecemos com essa mesma estrutura até os dias atuais onde aguardamos agora para o inicio de 2016 a inauguração da tão sonhada escola do PAC. 
Bom vale aqui registrar que 10 anos depois da nucleação também evoluiu gradativamente o transporte escolar, hoje a nossa escola esta equipada com transporte público do programa "caminho da escola". Não posso deixar de falar que também conquistamos através de muita luta a alimentação escolar de qualidade, pois hoje os nossos alunos tomam café da manhã e almoçam na escola devido a distancia a ser percorrido e o tempo que ficam no transporte escolar. Concluindo, posso dizer que foram muita luta, muita resistência, mas conseguimos evoluir muito na qualidade da educação oferecida em termos de aprendizado dos alunos, formação de professores, estrutura física da escola, alimentação escolar, transporte escolar e mesmo no desenvolvimento local. Temos muito ainda a conquistar e evoluirmos as toda essa experiência nos fez fortes suficiente para conquistarmos o melhor para os nossos alunos cada dia mais".

\subsection{2 - Escola Municipal Novo Horizonte (extensão)}

A Extensão da Escola Municipal Novo Horizonte era localizada a vinte e cinco quilômetros da escola Pau Brasil, numa comunidade denominada "Gleba Naves" que ali foram ocupados por lavradores e criadores de gado, local de difícil acesso, daí surge a necessidade em criar a referida extensão que havia somente um professor de nível fundamental, sendo uma sala multisseriadas do primeiro ano ao sétimo ano. Numa pesquisa feia com a ex-professora Luregina José de Carvalho, que faz o seguinte relato: Olha em 2005 quando comecei a trabalhar a estrutura era um barracão feito de tábua e a cobertura de lona com madeiramento roliço. Os bancos eram fixados no chão, nos primeiros anos não havia livros didáticos e os literários e trabalhava com sala multisseriadas (alunos da $1^{\mathrm{a}}$ a $7^{\mathrm{a}}$ série) com um total de 15 alunos. Merenda, bolacha e suco, em 2007 a merenda deu uma melhorada: Arroz, feijão, carne, bolacha, suco etc... Mas a estrutura continuou a mesma. A água para beber e fazer o lanche era extraída de uma mina d'agua apanhada e colocada em garrafas peti e alguns anos depois, no filtro de barro dessa situação permaneceu até o final de 2008 (nucleação). Durante esse período tive pouco acompanhamento da secretaria municipal de educação. 


\subsection{3 - Escola Municipal São Vicente}

A escola municipal São Vicente era localizada a oito quilômetros da escola Pau Brasil, dentro do assentamento São Vicente, ali residia parceleiros do INCRA, com economia na criação de gado e agricultura familiar, cultivo para sua subsistência, na escola havia duas professoras nível médio e magistério, sendo duas salas, a primeira com fundamental primeira fase multisseriadas e a segunda com fundamental segunda fase multisseriadas. Um depoimento colhido da professora Alda Monteiro de Carvalho Morais, relata que, a Escola São Vicente (extensão Pau Brasil) foi criada no ano de 2004. Como funcionária tinha apenas duas professoras (Alda e Selma), essas professoras faziam de tudo, davam aula, limpavam a escola e faziam a merenda. $\mathrm{O}$ salário era apenas de professora, merenda e limpeza saiam de graça, ou seja, não recebíamos salário para realizar esses serviços, fazíamos pensando na aprendizagem e no bem estar dos alunos. Era uma escola multisseriadas, " 1 a a $4^{\mathrm{a}}$ série juntas" e "5 a $8^{\mathrm{a}}$ série juntas”. Dizer que era fácil, não era, que os alunos tinham um ensino de qualidade não tinham, dúvidas por parte dos alunos surgiam a cada momento, fica difícil para o professor atender a todos ao mesmo tempo. Quando se fala de salas multisseriadas não estamos pensando num ensino de boa qualidade, sabemos que cada aluno tem o seu grau de dificuldade e tempo certo para aprender e assimilar o conhecimento científico em si. Hoje se continuar na mesma perspectiva de salas multi, também não teremos ensino de boa qualidade.

$\mathrm{Na}$ época, encontrávamos muitas dificuldades, porque não tínhamos suporte por parte da Secretaria de educação e nem dos assessores pedagógicos, ou seja, faltava o acompanhamento que temos hoje, como por exemplo, a formação continuada para os professores, troca de experiências e suporte no que nos almejamos. Lembro-me da falta de material didático e carteiras, os alunos sentavam em bancos improvisados pelos professores ou pelos pais, tinha aluno que as vezes sentavam no chão devido os bancos serem poucos. Também não tinha energia e nem água encanada. Para limpeza, merenda e água para beber, nós professores puxávamos da cisterna no balde. E mais, a limpeza do pátio da escola também era os professores que faziam como, por exemplo, (capinar de enxada, cortar de facão) e mais, quando tinha evento na escola a gente cozinhava no fogão a lenha e os alimentos para fazer o almoço era doados pelos pais e professores. A merenda diária dos alunos era apenas suco e bolacha. Essa era uma realidade que não 
queremos mais. Porém estamos presenciando as salas multi voltando em nossas escolas a cada ano que passa.

\section{3 - Revelando a Nucleação: comparando casos}

No estado de Santa Catarina foi implantado o programa de nucleação no final de 2007, para a secretaria municipal de educação o objetivo do município ao aderir o programa foi de ordem administrativa era mais vantajoso arcar com a despesa de transporte do que manter escolas abertas com poucos alunos, já para a secretaria de estado da educação e desporto o objetivo da nucleação era melhorar a estrutura física, promover melhores condições didáticas pedagógicas e serviço de apoio ao estudante.

Um aspecto a ser considerada no processo de nucleação de escolas è a nova forma de gestão educacional através de uma decisão política financeiro do governo federal voltado para o investimento em educação publica priorizando o ensino fundamental.

Em Confresa não foi tão diferente, no ano de 2004, ainda tínhamos quase todas as escolas do campo multisseriadas exceto as que hoje são núcleos, no entanto com promessas de melhoria na qualidade educacional e infraestrutura, abordam a proposta de nucleação das escolinhas que seriam aglomeradas em uma única unidade formando-se assim um núcleo. Pais, insatisfeitos manifestam-se uma vez que não queriam seus filhos estudando longe de casa, o que pouco adiantou, pois foram convencidos pelos gestores, e a nucleação aconteceu. 


\section{4 - Revelando os resultados da Nucleação}

Como ponto positivo: $\mathrm{O}$ aluno terá a oportunidade de estudar em uma escola maior tendo recursos, bem como o direito de estar interagindo com os colegas (pessoas) de diferentes culturas podendo eles ser da área rural ou urbana.

Por outro lado: Temos uma comunidade que perdeu sua escola, seu ponto de referencia, a liberdade em estarem participando das atividades da escola e o contato que tinham com o professor. Devido a distancias das residências ate a escola onde seus filhos estudam muitas famílias não tem participação mínima nas atividades escolar, perdendo toda a ligação que poderia uni-las ao acompanhamento do desenvolvimento educacional e intelectual de seus filhos.

A educação atende aos mais variados interesses políticos, econômicos e sociais, estando presente desde a montagem do currículo escolar até a discussão em torno do que deve ser estudado, quem deve estudar e como deve se estudar. (BEZERRA NETO, 2009, P.3)

Com esse novo modelo de educação as escolas do campo perdem uma parcela significativa de seus alunos para as da área urbana, em especial aquelas que eram multisseriadas e unidocentes, fazendo com que o aluno perdesse ainda a sua identidade do campo passando assim a ter que adotar a dos povos da cidade.

Com a aglomeração das escolas rurais em torno de novos núcleos, os gestores tinham como anseio por fim nas salas multisseriadas e ofertar melhores condições de ensino no campo. O agrupamento não é exclusividade do Brasil, ele ocorre de modo semelhante em outros países como Líbano, Irã, Costa Rica, Estados Unidos e Índia (VASCONCELLOS, 1993).

Podemos perceber que a política publica no que diz respeito ao processo de nucleação veio acompanhado por uma tentativa do Governo em diminuir o número de salas multisseriadas e escolas unidocentes, além do argumento de melhorar a qualidade da educação em áreas rurais, no entanto, observamos que ele trouxe para aqueles que residem no campo um novo impasse: o distanciamento da escola e a consequente 
necessidade de sujeitar seus filhos, diariamente, ao transporte quase sempre em condições inadequadas.

Ao longo desse processo, nossos gestores buscaram mostrar seus interesses em erradicar as salas multisseriadas no meio rural Contudo, notamos que pouco mais de seis anos as salas multisseriadas estão de volta em nosso município, especificamente no ano de 2014 e 2015.

Ao concretizar a nucleação das escolas do campo os governantes pensaram primeiramente, na redução de gastos deixando de lado os princípios humanos, pois justificaram qualidade no ato educacional e na infraestrutura coisa que pouco foi modificado, e o pior de tudo é que retrocedemos a multisseriação.

Conforme Santos os alunos residentes da zona rural "têm os marcadores de sua identidade negados, sobretudo pelo modelo curricular padronizado, elaborado a partir de categorias urbanocêntricas e que os obriga a negar a sua identidade cultural, sob pena de serem expulsos da escola (evasão e repetência)". (SANTOS, 2003).

\section{1- QUAIS OS MOTIVOS LEVARAM A GESTÃO MUNICIPAL EM FAZER A REFERIDA NUCLEAÇÃO?}

Reduzir gastos na folha de pagamento com professores, melhorar o ensino aprendizagem em núcleos estruturados de melhor qualidade com professores qualificados, merenda de boa qualidade e infraestrutura adequada.

2- COMO FUNCIONAVAM AS SALAS ENEXAS CHAMADAS DE EXTENSÃO E QUAL ERA A FORMAÇÃO DESSES PROFESSORES?

Essas salas de aula, chamadas na época de extensão, funcionavam distantes da escola maior, geralmente nas fazendas e acesso ruim para deslocamento de transportes. Os professores dessas extensões, alguns não possuíam o ensino fundamental completo e a merenda escolar consistia apenas em bolacha e suco. 
3- QUAL FOI A REAÇÃO DOS PAIS DE ALUNOS EM RELAÇÃO A DEMANDO DO TRANSPORTE À NUCLEAÇÃO?

$\mathrm{Na}$ época, os pais ficaram revoltados, conforme relatos, eles sentiam insegurança em colocar seus filhos dentro de um veículo, todos os dias, por um período longo (aproximadamente 2 horas) e distante das suas casas na escola núcleo.

\section{4- A ESTRUTURA DA ESCOLA NUCLEADA É ADEQUADA AO PROCESSO PELA QUAL SE PASSOU?}

A intenção da nucleação seria planejada com uma estrutura ideal, com salas adequadas, cantina, secretaria, laboratório de informática, e professores qualificados e formados na área e merenda escolar de qualidade. Porem, não aconteceu o que estava planejado, tudo ocorreu ao contrario, porem permaneceu a "dita" nucleação com sala de madeira, telhado de amianto, piso de terra batida, e professores ainda sem formação em área.

\section{Considerações finais}

Quero chamar atenção dos leitores desse trabalho para que possa compreender a magnitude de um processo de nucleação que inicia seus mecanismos para cumprir uma determinação de um gestor público municipal e seus colaboradores no tocante pela criação de políticas publicas educacionais do munícipio de Confresa, estado de Mato Grosso especificamente no ano de 2006. Para entender esse processo, foi necessário leituras, pesquisas, ouvir depoimentos de pessoas ligadas ao processo na época, buscar informações de todo contexto vivenciado naquele tempo. Percebemos que houve mudanças radicais que mexeram na estrutura física, pessoal e emocional das pessoas, uma vez que aconteceram grandes transformações nas escolas do campo conhecidas como núcleos escolares extinguindo escolas pequenas multisseriadas e sendo atendidas noutra escola maior com mais recursos didáticos, profissionais e merenda escolar de qualidade. Ao concluir esse trabalho, percebo que muito ainda tem de ser feito na 
prática e teoria de uma educação voltada para o Campo, nas perspectivas dos pensadores da educação que afirma: Caldart, Freire, Arroyo, Santos, Vasconcellos, Bezerra Neto e Andrade.

\section{Bibliografia}

Fabio Josué Souza dos Santos - Nem “TABARÉU/DA" NEM "DOUTOR/A": O (a) aluno da roça na escola da cidade - um estudo sobre Identidade e escola- Salvador - BA $[\mathrm{S} / \mathrm{N}] 2005$

Educação do Campo: Referencias Teóricas em Discussão - Luiz Bezerra Neto, Maria Cristina dos Santos Bezerra - artigo HTTP://br.bing.com/search? Acessado em 28/08/2013

BRASIL. LEI DE DIRETRIZES E BASES DA EDUCAÇÃO NACIONAL - LDB. Lei $\mathrm{n}^{\circ} 9.394$ de dezembro de 1996. MEC.

Mato Grosso. Secretaria de Estado de Educação. Orientações curriculares: Diversidades Educacionais./ Secretaria de Estado de Mato Grosso. Cuiabá: Defanti, 2010.

Teoria e prática da educação do campo: análises de experiências/organizadoras, Carmem Lúcia Bezerra Machado; Christiane Senhorinha Soares Campos; Conceição Paludo - Brasília: MDA, 2008.

Gadotti, Moacir. Pedagogia: diálogo e conflito / Moacir Gadotti, Paulo Freire e Sérgio Guimarães. 4 ed. - São Paulo: Cortez, 1995. 

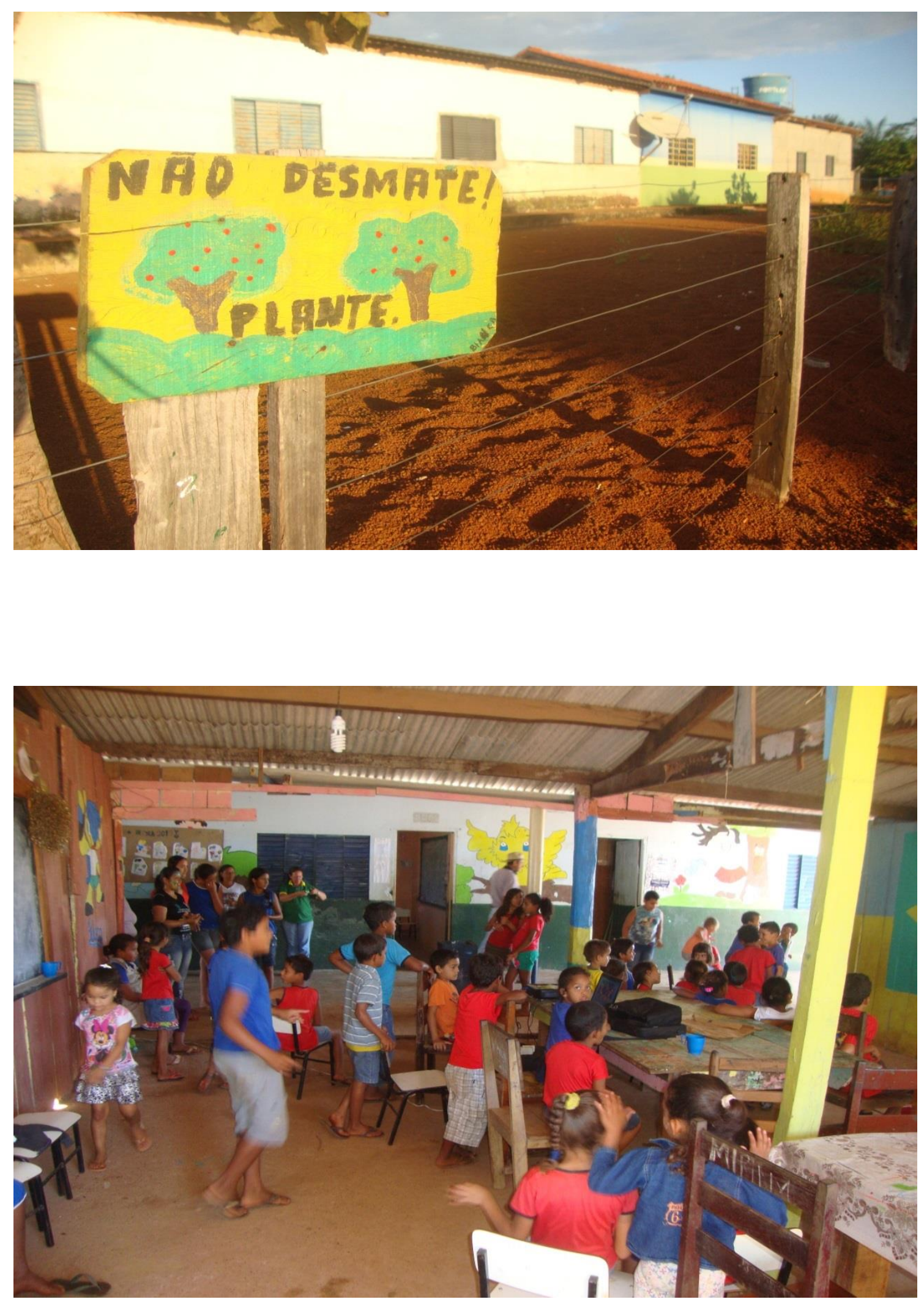
